Original Research Paper

\title{
PENGARUH SISTEM ANTRIAN BERBASIS QUICK RESPONSES CODE \\ TERHADAP BEBAN KERJA PETUGAS LOKET PENDAFTARAN \\ DI RUMAH SAKIT UMUM SURYA HUSADHA DENPASAR
}

\section{Rai Riska Resty Wasita*, Agus Donny Susanto}

Program Studi Perekam dan Informasi Kesehatan, Fakultas Kesehatan, Sains, dan Teknolgi,

Universitas Dhyana Pura

Email Corresponding*:

riskaresty@undhirabali.ac.id

Page : 24-29

\section{Kata Kunci :}

QR Code, beban kerja, loket pendaftaran

Keywords:

QR code, workload, patient counter

\section{Published by:}

Tadulako University,

Managed by Faculty of Medicine.

Email: healthytadulako@gmail.com

Phone (WA): +6285242303103

Address:

Jalan Soekarno Hatta Km. 9. City of

Palu, Central Sulawesi, Indonesia
Berdasarkan data tahun 2020, rata-rata kunjungan pengguna asuransi Badan Penyelenggara Jaminan Sosial (BPJS) Kesehatan di Rumah Sakit Surya Husadha Denpasar berkisar 6000 kunjungan per bulannya sehingga sering terjadi penumpukan antrian di loket pendaftaran pasien. Hal ini secara tidak langsung menambah beban kerja petugas loket yang harus menginput data pasien satu per satu secara manual. Tidak jarang terjadi kelelahan sehingga menurunkan kinerja serta menambah tingkat kesalahan petugas sehinnga memberikan peluang yang lebih besar untuk terjadi kecelakaan kerja. Tujuan penelitian ini untuk mengidentifikasi pengaruh sistem antrian berbasis $Q R$ code terhadap beban kerja petugas loket pendaftaran di rumah sakit. Penelitian ini merupakan penelitian kuantitatif dengan pendekatan quasi eksperimen one group prettes-posttes. Pengambilan sampel dilakukan pada 20 petugas loket pendaftaran BPJS dengan menggunakan teknik sampling jenuh. Pengembangan sistem QR code menggunakan System Development Life Cycle (SDLC). Pengumpulan data dilakukan dengan menyebarkan kuesioner sebelum dan setelah petugas diberikan intervensi QR Code. Analisis yang digunakan yaitu uji Paired T-tes untuk melihat pengaruh QR Code terhadap beban kerja petugas sebelum dan setelah diberikan QR Code. Hasil penelitian menunjukkan hasil pre test dan post test beban kerja diperoleh nilai signifikansi ( $p$-value) sebesar 0,002 yang bermakna bahwa terdapat perbedaan yang signifikan antara rata-rata beban kerja pre-test dan post-test setelah penggunaan sistem atrian berbasis $Q \mathrm{R}$ Code.

\section{ABSTRACT}

Based on data from 2020, the average visit of Health Nation Insurance (BPJS) users at Surya Husadha Hospital Denpasar is around 6000 visits per month, so there is often a buildup of queues at the patient registration counter. This indirectly adds to the workload of the counter staff who have to manually input patient data one by one. It is not uncommon for fatigue to occur so that it reduces performance and increases the error rate of officers so as to provide a greater opportunity for work accidents to occur. The purpose of this study was to identify the effect of a QR code-based queuing system on the workload of the registration counter staff at the hospital. This research is a quantitative study with a quasi-experimental approach to one group pretests-posttest. Sampling was carried out at 20 BPJS registration counter officers using a saturated sampling technique. QR code system development using the System Development Life Cycle (SDLC). Data was collected by distributing questionnaires before and after the officers were given the QR Code intervention. The analysis used is the Paired T-test to see the effect of the QR Code on the workload of the officers before and after being given the $Q R$ Code. The results showed that the workload pre-test and post-test results obtained a significance value (p-value) of 0.002, which means that there is a significant difference in the average workload between the pre-test and post-test after using the QR Code-based attrition system.. 


\section{PENDAHULUAN}

Pelayanan rumah sakit yang baik memerlukan tata kerja yang tertib, rapi, teliti, dan cepat. Rumah sakit harus memberikan pelayanan yang terbaik agar pasien mendapatkan pelayanan yang maksimal. Salah satu pelayanan yang kerap kali menjadi sorotan adalah sistem antrian karena pasien sering mengeluhkan lamanya antrian hingga proses keluar dari rumah sakit ${ }^{1}$. Operasional rumah sakit harus dapat berjalan efektif dan efisien, maka perlu dilakukan pembangunan di bidang infrastruktur melalui penerapan teknologi ${ }^{2}$.

Pesatnya perkembangan teknologi di tengah berbagai aspek kehidupan masyarakat memunculkan berbagai inovasi-inovasi baru untuk mempermudah pekerjaan manusia. Dalam perkembangannya, sistem teknologi berbasis Quick Responses (QR) Code menjadi salah satu sistem yang dapat diaplikasikan di rumah sakit guna mempermudah pekerjaan khususnya pada layanan pendaftaranan pasien. QR Code merupakan jenis kode yang mampu menyampaikan informasi dengan cepat dan tetap mendapat respon yang cepat ${ }^{3}$. Sistem kendali antrian di rumah sakit yang menggunakan QR Code dapat berfungsi sebagai verifikasi kedatangan pasien sehingga mampu menyediakan layanan yang efektif untuk memudahkan pasien dalam hal administrasi ${ }^{4}$.

Rumah Sakit Umum (RSU) Surya Husadha Denpasar merupakan salah satu rumah sakit yang sudah menerapkan teknologi dan informasi kesehatan pada beberapa sektor layanan kesehatannya. Dari beberapa sektor tersebut masih dijumpai kendala khususnya mengenai antrian pasien pengguna layanan asuransi kesehatan Badan Penyelenggara Jaminan Sosial (BPJS) Kesehatan. Mayoritas pengguna layanan rumah sakit meggunakan layanan BPJS Kesehatan sebagai asuransi kesehatan. Berdasarkan data tahun 2020, ratarata kunjungan pasien yang menggunakan asuransi BPJS Kesehatan di RS Surya Husadha setiap bulannya kurang lebih 6000 kunjungan baik itu kunjungan pasien rawat jalan maupun rawat inap sehingga pada loket BPJS sering mengalami penumpukan antrian. Hal ini secara tidak langsung menambah beban kerja petugas yang harus menginput data pasien satu per satu secara manual. Tidak jarang terjadi kelelahan sehingga menurunkan kinerja serta menambah tingkat kesalahan petugas. Meningkatnya kesalahan kerja akan memberikan peluang yang lebih besar untuk terjadi kecelakaan kerja 5 . Hal ini secara tidak langsung menyebabkan terjadinya kendala-kendala yang menimbulkan penurunan nilai produktifitas. Selain itu, apabila terjadi antrian panjang dan ketidakteraturan maka pasien juga harus rela mengantri dan menghabiskan waktu hingga antrian mencapai gilirannya. Hal ini menjadi kurang efektif dan kerapkali menimbulkan ketidaknyamanan pasien ${ }^{6}$.

Penelitian Chang et al., (2015) dengan menggunakan sistem layanan aplikasi pengambilan gambar medis melalui otentikasi QR code berbasis sistem operasi Android digunakan untuk skrining gambar usus besar. Hasil percobaan menunjukkan sistem QR code efisien untuk mengamati polip saluran cerna ${ }^{7}$. Hal ini diperkuat dengan penelitian Paramarta et al., (2018) menunjukkan sistem informasi medis menggunakan barcode berbasis desktop dan android secara efektif dan efisien menampilkan data informasi pasien ke dokter melalui scan barcode yang ditampilkan di android dan aplikasi desktop dapat memperbaharui data informasi pasien serta dokter ${ }^{8}$. Penggunaan QR code juga mampu membantu menangani penelusuran berkas, kelengkapan berkas, dan penyimpanan berkas rekam medis ${ }^{9}$.

Berdasarkan uraian di atas, dibutuhkan sebuah sistem informasi yang dapat menjadi sebuah inovasi layanan publik. Tujuan penelitian ini untuk mengidentifikasi pengaruh sistem antrian berbasis $Q R$ code terhadap beban 
kerja petugas loket pendaftaran BPJS Kesehatan di rumah sakit.

\section{BAHAN DAN CARA}

Penelitian ini merupakan penelitian kuantitatif dengan desain penelitian quasi eksperimen one group pretest-posttest design dimana petugas pendaftaran loket BPJS akan diukur beban kerja sebelum diberikan perlakuan dan diobservasi kembali sesudah diberikan perlakuan QR Code. Waktu pengambilan data dilakukan pada Bulan Oktober sampai November 2021 dengan lokasi penelitian di RSU Surya Husadha Denpasar. Penentuan sampel dilakukan dengan metode total sampling sebanyak 20 orang petugas loket di bagian pendaftaran BPJS Kesehatan.

Instrumen penelitian yang digunakan adalah QR code dan kuesioner beban kerja. QR code dikembangkan dengan menggunakan Sistem QR code ini menggunakan website sebagai sarana yang dapat diakses oleh pengguna. Selama proses registrasi, penggunaa akan memasukkan data diri dan keluhannya, pilihan dokter di website dan kemudian akan divalidasi oleh admin yang bertugas di bagian loket pendaftaran.

Kuesioner beban kerja terdiri dari tiga aspek yaitu beban kerja fisik, psikologis dan waktu. Kuesioner akan diuji untuk melihat validitas dan reliabilitasnya. Selanjutnya untuk melihat sebaran data pre dan post beban kerja digunakan uji normalitas Shapiro-wilk. Kemudian dianalisis statsitik dengan menggunakan uji Paired T-test. Penelitian ini sudah lolos kelaikan etik dari Komisi Etik Penelitian Fakultas Kedokteran Universitas Udayana dengan nomor 2803/UN14.2.2.VII.14/LT/21.

\section{HASIL}

\section{Uji validitas dan reliabilitas}

Berdasarkan hasil pengujian pada kuesioner beban kerja, dari 30 pertanyaan diperoleh hasil bahwa keseluruhan butir pernyataan dikatakan valid, yaitu nilai Corrected Item Total Correlation berkisar antara 0,507-0,921. Hal tersebut menandakan bahwa nilai yang diperoleh pada masing-masing butir pernyataan memiliki nilai yang lebih besar jika dibandingkan dengan $r$ table.

Hasil uji reliabilitas pada kuesioner beban kerja didapatkan nilai Crombach Alpha= 0,977, sehingga pertanyaan pada kuesioner beban kerja dinyatakan reliabel.

\section{Karakteristik sampel penelitian}

Penelitian ini menggunakan sebanyak 20 sampel petugas loket di RSU Surya Husadha Denpasar yang diambil dengan metode total sampling. Keseluruhan sampel akan dianalisis berdasarkan jenis kelamin, usia, pendidikan, dan lama bekerja.

Berdasarkan Tabel 1 responden berada pada kelompok $\leq 27$ tahun sebesar 50\%. Responden berjenis kelamin laki-laki sebanyak $55 \%$ dan responden perempuan sebanyak $45 \%$. Sebagian besar responden berada pada kelompok lama kerja $\leq 3$ tahun yaitu sebesar $60 \%$. Pendidikan terakhir responden dominan pada jenjang SMA/SMK yaitu 50\%, Diploma sebesar 35\%, dan lulusan Strata I sebesar $15 \%$.

\section{Tabel 1. Distribusi Karakteristik}

\begin{tabular}{lcc}
\multicolumn{3}{c}{ Responden (n = 20 Orang) } \\
\hline Karakteristik & $\begin{array}{c}\text { Frekuensi } \\
\text { (Orang) }\end{array}$ & $\begin{array}{c}\text { Proporsi } \\
(\%)\end{array}$ \\
\hline Umur & 10 & 50 \\
$\leq 27$ & 10 & 50 \\
$>27$ & & \\
& & \\
Jenis Kelamin & 11 & 55 \\
Laki-laki & 9 & 45 \\
Perempuan & & \\
& & \\
Lama Bekerja & 12 & 60 \\
$\leq 3$ Tahun & 8 & 40 \\
$>3$ Tahun & & \\
& & \\
Riwayat Pendidikan & 10 & 50 \\
SMA/SMK & 3 & 15 \\
D3 & 7 & 35 \\
S1 & & \\
\hline Sur priner & &
\end{tabular}

Sumber: primer 


\section{Uji Normalitas}

Uji normalitas digunakan untuk mengetahui sebaran distribusi data beban kerja pre dan pos tes dengan menggunakan uji Shapiro-wilk.

\section{Tabel 2. Hasil Uji Normalitas Variabel}

\begin{tabular}{lcc}
\hline Nama Variabel & P value & $\begin{array}{c}\text { Distribusi } \\
\text { Data }\end{array}$ \\
\hline Pre-Test & 0,109 & Normal \\
Post-Test & 0,064 & Normal \\
\hline
\end{tabular}

Hasil uji normalitas menunjukkan bahwa nilai signifikansi beban kerja untuk pre test sebesar 0,109. Hal ini berarti hasil pre test berdistribusi normal. Demikian juga dengan uji normalitas pos tes sebesar 0,064. Maka dari itu, nilai signifikansi pre-test dan post test lebih besar dari 0,05 . Hal ini berarti data beban kerja berdistribusi normal.

\section{Analisis Beban Kerja Pre dan Post Tes}

Uji hipotesis yang digunakan adalah Paired T-test. Hasil uji t-paired antara pre-test dan post-test diperoleh dengan nilai signifikansi (p-value) sebesar 0,002. Nilai signifikansi lebih kecil dari $0,05(0,002<0,05)$ sehingga menunjukkan terdapat perbedaan yang signifikan rata-rata skor beban kerja pre tes dan pos tes setelah penggunaan sistem berbasis QR code.

\section{Tabel 3. Uji Hipotesis}

\begin{tabular}{lcccc}
\hline $\begin{array}{l}\text { Beban } \\
\text { Kerja }\end{array}$ & Mean & SD & SE & $\begin{array}{c}\text { P } \\
\text { Value }\end{array}$ \\
\hline Pre-Tes & 96,65 & 14,939 & 3,341 & 0,002 \\
Pos-test & 82,30 & 12,537 & 2,803 & \\
\hline
\end{tabular}

\section{PEMBAHASAN}

Berdasarkan Tabel 3, menunjukkan bahwa beban kerja petugas sebelum penggunaan sistem antrian berbasis QR Code pada petugas loket BPJS Kesehatan berkisar pada rata-rata 96,65 dengan standar deviasi 14,939 dan standar error 3,341. Jika menggunakan cut of poit dengan 30 pertanyaan, rata-rata beban kerja petugas berada pada kategori beban kerja tinggi. Tingkat beban kerja yang berlebih dapat menyebabkan terjadinya kelelahan kerja. Kelelahan kerja memungkinkan terjadinya penurunan prestasi dan juga motivasi pekerja tersebut ${ }^{10}$. Beban kerja tinggi pada petugas loket disebabkan tugas kerja yang kompleks dan beban pekerjaan terlalu tinggi sehingga dapat mengakibatkan menurunnya produktivitas. Apabila menerima beban kerja berlebih dapat memicu terjadinya kelelahan baik fisik, mental dan reaksi-reaksi emosional ${ }^{11}$.

Banyaknya beban kerja atau tuntutan tugas yang diterima oleh pekerja harus sesuai atau seimbang terhadap kemampuan fisik, kemampuan kognitif dan keterbatasan manusia yang menerima beban tersebut ${ }^{12}$. Semakin tinggi beban kerja yang diberikan, semakin tinggi pula peluang terjadinya stres dan penurunan kinerja pada tenaga kerja ${ }^{13}$.

Pada Tabel 3, hasil penelitian beban kerja post tes menunjukkan bahwa beban kerja petugas setelah penggunaan sistem antrian berbasis quick responses code pada loket pendaftaran BPJS Kesehatan berada pada ratarata 82,30 dengan standar deviasi 12,537 dan standar error 2,803. Jika menggunakan cut of poit dengan 30 pertanyaan, rata-rata beban kerja petugas berada pada kategori beban kerja rendah. Beban kerja pada petugas loket berkurang disebabkan adanya sistem berbasis QR Code yang membuat tugas kerja petugas yang kompleks menjadi menjadi sangat mudah sehingga dapat mengakibatkan meningkatnya produktivitas kerja.

Adanya inovasi-inovasi di bidang teknologi mampu memudahkan pekerjan manusia. Hal ini secara tidak langsung dapat meringankan beban kerja baik secara fisik maupun mental sehingga produktivitas dalam bekerja dapat ditingkatkan. Efektivitas pemanfaatan teknologi berupa QR code bagi petugas loket pendaftaran dapat memberi 
kontribusi guna penyelesaian tugas-tugas adminstrasi pasien agar dapat dilaksanakan dengan baik. Hal itu dapat diperoleh dengan memanfaatkan teknologi informasi untuk menurunkan human eror, seperti lupa, turunnya presisi karena kelelahan, dan lain-lain ${ }^{14}$.

Berdasarkan pembahasan diatas peneliti berasumsi bahwa sistem teknologi berbasis QR Code menjadi salah satu sistem yang dapat diaplikasikan di rumah sakit guna mempermudah pekerjaan khususnya pada layanan pendaftaran pasien. Sistem antrian berbasis QR Code sangat dibutuhkan untuk memperbaiki sistem antrian yang sebelumnya dinilai kurang efisien karena masih menggunakan metode manual yang kerapkali menambah pekerjaan petugas. Sistem antrian berbasis QR Code memiliki kegunaan sebagai alat bantu bagi petugas antrian rumah sakit maupun pasien dalam hal pemanggilan maupun pengambilan nomor antrian. Sistem kendali antrian di rumah sakit yang menggunakan QR Code dapat berfungsi sebagai verifikasi kedatangan pasien sehingga mampu menyediakan layanan yang efektif untuk memudahkan pasien dalam hal administrasi. Dengan penggunaan sistem berbasis QR Code dapat membuat tugas dari petugas loket menjadi berkurang. Apabila beban kerja yang terima memadai sehingga menunjang kinerja serta mengurangi tingkat kesalahan petugas (Soedirman dan Suma'mur, 2014).

\section{KESIMPULAN DAN SARAN}

1. Hasil penelitian menunjukkan bahwa ratarata beban kerja petugas sebelum penggunaan sistem berbasis QR code adalah 96,65 dengan standar deviasi 14,939.

2. Hasil penelitian menunjukkan bahwa ratarata beban kerja petugas setelah pengunaan sistem berbasis QR code adalah 82,30 dengan standar deviasi 12,537.

3. Hasil penelitian menunjukkan hasil pre test dan post test beban kerja diperoleh nilai signifikansi ( $p$-value) sebesar 0,002. Nilai signifikansi uji (p-value) lebih kecil dari 0,05 yang bermakna bahwa terdapat perbedaan yang signifikan rata-rata beban kerja antara pre-test dan post-test setelah penggunaan sistem atrian berbasis quick response code.

Berdasarkan hasil yang telah diuraikan diatas, maka dapat diberikan saran agar manajemen rumah sakit ikut mempelajari adanya perkembangan teknologi yang semaksimal mungkin agar dapat mengembangkan sistem yang lebih sempurna dan dapat menjadi bahan advokasi kepada pemegang kebijakan dalam penyusunan dan pengembangan program manajemen rumah sakit guna pemberian layanan yang efektif dan efisien serta mempermudah proses pelayanan dalam menyediakan informasi yang dibutuhkan oleh manajemen rumah sakit. Selain itu dengan adanya teknologi yang baru, petugas loket juga harus diberikan pelatihan agar mampu mengoperasikan teknologi yang ada guna meningkatkan efisiensi dan efektivitas dalam bekerja.

\section{UCAPAN TERIMA KASIH}

Penulis mengucapkan terima kasih Direktur Rumah Sakit Umum Surya Husadha Denpasar, petugas loket BPJS Kesehatan di RSU Surya Husadha, dan Universitas Dhyana Pura atas kesempatan yang diberikan kepada peneliti untuk menyelesaikan penelitian ini. Semoga bermanfaat untuk ilmu pengetahuan.

\section{DAFTAR PUSTAKA}

1. Mousavi SM, Pourshariati F, Rajabi G, Letafatnejad M. Waiting Time to Receive Healthcare Services and Factors Affecting It: Case Study in a University Hospital. Evid Based Heal Policy, Manag Econ. 2017;1(2).

2. Su Q, Yao X, Su P, Shi J, Zhu Y, Xue L. Hospital Registration Process Reengineering Using Simulation Method. $J \quad$ Healthc Eng. 2010;1:895865. doi:10.1260/2040-2295.1.1.67 
3. Taveerad N, Vongpradhip S. Development of Color QR Code for Increasing Capacity. In: 2015 11th International Conference on Signal-Image Technology Internet-Based Systems (SITIS). ; 2015:645-648. doi:10.1109/SITIS.2015.42

4. Hendra R, Perdana Y, Taufik M, Rakhmania AE. Hospital Queue Control System using Quick Response Code ( QR Code ) as Verification of Patient' $\mathrm{s}$ Arrival. Int $J$ Adv Comput Sci Appl. 2019;10(8):357-363.

5. Nurmianto E. Ergonomi: Konsep Dasar Dan Aplikasinya. Guna Widya; 2004.

6. Salim JN, Suseno JE, Nurhayi OD. Hybrid Method of First Come First Served and Priority Queue for Queue System in Hospital. Int $J$ Comput Appl. 2018;182(10):15-22.

doi:10.5120/ijca2018917713

7. Chang Y, Yan S, Lin P, Zhong H. A mobile medical QR-code authentication system and its automatic FICE image evaluation application. 2015;13:220-229.

8. Paramarta I, Sudarma M, Swamardika A. Perancangan Aplikasi Sistem Inforamsi Medis Menggunakan Barcode Berbasis Desktop dan Android. J SPEKTRUM. 2018;4:16.

doi:10.24843/SPEKTRUM.2017.v04.i02. p03
9. Kurniawan AA, Utomo DW. QR Code Mobile sebagai Pendukung Rekam Medik Berkas Rawat Jalan RS. St. Elisabeth Semarang. $J$ Inform $J$ Pengemb IT. 2018;03(01):86-95.

10. Setyawati. Selintas Tentang Kelelahan Kerja. Asmara Books; 2010.

11. Manuaba. Ergonomi Kesehatan Dan Keselamatan Kerja. PT Guna Widya Surabaya; 2000.

12. Tarwaka. Ergonomi Industri Dasar-Dasar Pengetahuan Ergonomi Dan Aplikasi Di Tempat Kerja. Harapan Press; 2015.

13. Manabung AR, Suoth LF WF. Hubungan antara Masa Kerja dan Beban Kerja dengan Stres Kerja pada Tenaga Kerja di PT. Pertamina TBBM Bitung. Kesmas. 2018;7(5).

14. Uno H, Lamatenggo N. Teori Kinerja Dan Pengukurannya. PT Bumi Aksara; 2012.

15. Soedirman, Suma'mur. Kesehatan Kerja Dalam Perspektif Hiperkes \& Keselamatan Kerja. Erlangga; 2014. 